Classification: Social Sciences

Raising White Resisters: Studying the Development of Anti-Racist White Children and Youth

\author{
*Taylor Hazelbaker \\ Department of Education \\ University of California, Los Angeles \\ 3302 Moore Hall, Los Angeles, CA 90095 \\ Christia Spears Brown \\ University of Kentucky \\ Lindsey Nenadal \\ California State University, Chico \\ Rashmita S. Mistry \\ University of California, Los Angeles
}

Date submitted: March 21, 2021

This manuscript has been submitted for publication and is not the final version

*Corresponding Author: taylorrae1793@ucla.edu 


\title{
Raising White Resisters: Studying the Development of Anti-Racist White Children and Youth
}

\begin{abstract}
This article presents a developmental model of anti-racism among White children and youth. The model is informed by a structural-psychological framework which situates the development of anti-racism as inseparable from the structures and systems that uphold racial inequality. In articulating the processes by which children and early adolescents move toward becoming antiracists, the model emphasizes foundational abilities (e.g., socio-cognitive and moral development), a developing sense of self and society (e.g., recognition of racism, understanding of White privilege), and the importance of anti-racism action (e.g., interpersonal and collective action) and promotive contexts (e.g., ethnic-racial socialization, critical consciousness). The paper concludes with a research mandate for developmental scholars studying the development of anti-racism among White children and youth.
\end{abstract}

Keywords: Anti-Racism, White children, White privilege 


\section{Raising White Resisters: Studying the Development of Anti-Racist White Children and}

\section{Youth}

Anti-racism is "a system of equity based on race that is created and maintained by a dynamic interplay between psychological factors (i.e., equitable thoughts, feelings, and actions) and sociopolitical factors (i.e., equitable laws, policies, and institutions)" (Roberts \& Rizzo, 2020, p. 9). For White individuals, anti-racism includes an understanding of racism and White privilege paired with a commitment to behaviors that challenge racism (Seaton, 2020). Current events of the past five years - the White supremacist insurrection of the U.S. Capitol, the racial justice uprisings following the murder of George Floyd, and the racist remarks and policies enacted by the Trump administration - have once again elevated conversations about race and racism in the United States, including the pressing need for anti-racist policies and actions. This is particularly true for individuals who are White, many of whom are "waking up" to the racialized realities of people of color, particularly Black people, in the United States. To foster anti-racism, White individuals also need to "wake up" to the racialized realities of Whiteness and the need to better educate White children about White supremacy and White privilege. The current paper puts forth a developmental model of anti-racism among White children and youth.

\section{Defining Race, Racism, and Anti-Racism in the Context of the United States}

While race, racism, and anti-racism are not specific to the United States and aspects of our developmental model and research agenda may generalize to other contexts, our paper is positioned within the unique historical and contemporary context of the United States. We recognize that race is socially constructed and often thought about in terms of shared physical characteristics such as skin color (Richeson \& Sommers, 2016). Notions of race, however, are not solely based on physical characteristics but also influenced by social norms and laws. 
Historically, the racial category of who is considered White has shifted. For example, the "onedrop rule" defined Whiteness based on the percentage of one's ancestors of African descent and was put in place to maintain the position of power held by White individuals so that only individuals who were fully White could own property, work, and vote (Roberts \& Rizzo, 2020). Waves of immigration have also shifted societal notions of Whiteness. In the 1900s, for example, Jewish, Irish, and Italian Americans were not considered White, while Arab Americans had often been labeled as White prior to, but not after, the 9/11 terrorist attacks (Richeson \& Sommers, 2016). The 2020 Census delineates that 'White' includes those who identify with groups from Europe, the Middle East, or North Africa (U.S. Census, 2020).

Whiteness includes "the overt and subliminal socialization processes and practices, power structures, laws, privileges, and life experiences that favor the White racial group over all others" (Helms, 2017, p. 718). Scholars describe Whiteness as multidimensional: it is a position of advantage, provides the ability to see oneself outside of race (i.e., as just human), and is a set of unnamed, yet normative, cultural practices (Helms, 2017; Roberts \& Rizzo, 2020). For much of U.S. history, Whiteness has been viewed as normative with the benefits of racism invisible to White people who do not recognize White privilege and the social norms that maintain it (Helms, 2017; McIntosh, 2012). For White children and youth to become anti-racist, however, systems of power and privilege cannot remain invisible and left unchallenged (McIntosh, 2012).

Racism is "not only a personal ideology based on racial prejudice but a system involving cultural messages and institutional policies and practices as well as the beliefs and actions of individuals" (Tatum, 2017, p. 87). In other words, racism is embodied in biased attitudes and beliefs, biased media, biased policies, and biased institutions. In the United States, racism advantages White people and disadvantages people of color (Roberts \& Rizzo, 2020; Tatum, 
2017). Racism has deep-seated roots in the kidnapping, enslavement, and murder of people of African descent and Indigenous people in what is now the United States. It has been maintained through oppressive immigration policies, forced racial segregation, and voter suppression. Racism continues today in disparities in wealth, healthcare, mass incarceration, the quality of and access to housing and education, as well as the murders of Black Americans at the hands of the police, deportation of undocumented immigrants, and the separation of children from their families at U.S. borders (Richeson \& Sommers, 2016; Roberts \& Rizzo, 2020).

As previously defined, anti-racism includes the psychological and sociopolitical factors that produce "a system of equity based on race" (Roberts \& Rizzo, 2020, p. 9). We further operationalize anti-racism as a continual process of self-examination of one's own thoughts and feelings, learning about racism, and engaging in anti-racism action. Anti-racism action, according to Aldana and colleagues (2019), includes interpersonal, communal, and political actions that challenge racism. We use interpersonal action to describe individual behaviors enacted by children and youth to challenge racism in their proximal environments (e.g., bystander intervention, challenging a racist comment). The term collective action describes communal (e.g., joining an anti-racist organization at school) and political (e.g., attending a Black Lives Matter protest) behaviors that challenge structural racism (Aldana et al., 2019).

\section{Anti-Racism in Childhood and Adolescence}

The development of anti-racism must begin early in life for White individuals. Research demonstrates that White children are capable of labeling themselves and others according to race by age four (Pauker et al., 2016) and report racial bias by around age seven (Raabe \& Beelman, 2011). Children's racial awareness continues to develop across middle childhood parallel to the development of more advanced socio-cognitive and moral reasoning skills (Quintana, 2008). 
Early adolescence (i.e., ages 9 - 14) is a key developmental period for the development of antiracism among White youth. The development of more advanced socio-cognitive abilities (e.g., empathy, social perspective-taking) allow adolescents to think more abstractly about race, more critically examine social issues, and develop a more complex understanding of inequality (Elenbaas et al., 2020; Quintana, 2008). Promoting anti-racism early in life is likely to facilitate more and longer-term benefits at both the individual- (e.g., positive interactions with people of color) and structural- (e.g., political engagement) level.

\section{Theoretical Framework: A Structural-Psychological Approach}

Guided by Syed and McLean (2020) we take a structural-psychological approach when outlining a developmental model and research agenda for the study of anti-racism among White youth. We acknowledge that the development of anti-racism does not occur outside of structural factors and systems that uphold racial inequality (e.g., White supremacy) but are inseparable from them. As Syed and McLean argue, these are "not just 'contexts' in which individuals develop, but rather are part of the fabric of their everyday lives" (p. 4).

The current paper draws on the master narrative framework which outlines three coexisting narratives: master narratives which are "culturally shared stories that guide thoughts, beliefs, values and behaviors" (Syed \& McLean, 2020, p. 3), personal narratives which are stories shared by individuals and used to form their identities, and alternative narratives which are stories that challenge the master narratives (McLean \& Syed, 2015). The master narrative approach pays attention to both the content of how these narratives are defined and the processes for how individuals negotiate and internalize them (Syed \& McLean, 2020). One's personal narrative is shaped by and shapes the master and alternative narratives. For example, some individuals accommodate master narratives by - often unconsciously - incorporating them into 
their personal narratives. Other individuals resist master narratives by consciously and actively aligning their personal narrative with an alternative narrative. Individuals who are part of marginalized groups are more likely to resist master narratives while dominant group members (e.g., White individuals) are more likely to accommodate them (Syed \& McLean, 2020).

In the current paper, we focus on two master narratives that uphold racial inequality: (a) White supremacy, the cultural script that positions White people as superior in the racial hierarchy and Whiteness as ideal (Roberts \& Rizzo, 2020); and (b) colorblindness, the belief that race does not matter, and everyone is the same (Neville et al., 2013). We argue that the alternative narrative for White individuals is anti-racism. To resist these master narratives, White individuals must understand the cultural script they are resisting. However, the structures that maintain power and privilege tend to be invisible to White individuals (McIntosh, 2012) who may not be motivated to resist a narrative that upholds their position of power. It is pertinent to understand when and how White individuals resist the master narratives of White supremacy and colorblindness and instead align with an alternative narrative of anti-racism. Such master narratives are embedded in the environments in which White children and youth spend their time (e.g., standards of beauty and preference for straight hair, stereotypical media representations of people of color, the omission of people of color from school curriculum; Tatum, 2017). Master narratives (often implicitly) influence development early in life, so it is important to understand how master and alternative narratives are being experienced by and socialized to White youth.

\section{A Developmental Model of Anti-Racism Among White Children and Youth}

In setting a research agenda for studying the development of anti-racism among White youth, we heed Roberts and Rizzo's charge to “shift our attention away from how people become racist, and toward the contextual influences, psychological processes, and developmental 
mechanisms that help people become anti-racist" (p. 10). We focus on the developmental periods of childhood and early adolescence because the attitudes and beliefs contributing to anti-racism start early in life. The goal of our model is to outline the processes that contribute to the development of anti-racist White youth in childhood through adolescence (see Figure 1).

Our proposed model is split into two developmental periods: childhood (ages $3-8$ ) and early adolescence (ages 9 -14). Each developmental period contains four components. The first component of the developmental model outlines the foundational abilities (e.g., socio-cognitive skills, such as perspective-taking and moral reasoning) that contribute to the development of anti-racism within each developmental period. The second - and primary - component details the understanding of self and society that White children and youth must acquire to become antiracist. In childhood, White children need to learn to identify as White and recognize bias and racism at the individual level. In early adolescence, White youth must recognize social inequality and racism at the structural level and understand White privilege. An understanding of self and society leads to the third component of the model which describes the anti-racism action taken by children and youth to challenge racism. We posit that the type of action differs across developmental periods. For instance, learning to identify as White and recognizing bias and racism at the individual level may lead to interpersonal action (e.g., bystander intervention or challenging a racist comment or behavior). On the other hand, developing a more complex understanding of racism that includes structural inequality and White privilege will foster antiracist collective action (e.g., communal and political actions such as attending a protest).

It is important to note that the development that occurs during childhood is necessary for the continued progress toward anti-racism in early adolescence. However, developing an understanding of self and society in childhood does not guarantee continuation of the path to 
anti-racism in adolescence. In fact, many White children and youth remain at an individual-level understanding of racism. We argue that the bridge from understanding individual racism and engaging in interpersonal action to a structural understanding of self and society requires the development of more complex socio-cognitive and moral reasoning skills paired with promotive contexts that scaffold youths' structural understanding of racism. Thus, the fourth component describes the promotive contexts (i.e., ethnic-racial socialization and critical consciousness) for the development of anti-racism. These contexts support anti-racism at all developmental levels.

\section{Foundational Abilities}

As Roberts and Rizzo (2020) highlight, anti-racism is partly comprised of psychological factors that include "equitable thoughts [and] feelings" (p. 10). Therefore, we must consider the foundational abilities that begin to develop during childhood that contribute to the development of anti-racism. These include socio-cognitive development, moral development, and an awareness of race. These foundational abilities become more advanced in early adolescence and support an understanding of the systems and structures of inequality (Quintana, 2008).

Socio-Cognitive Development. Social categorization, in which humans (as social beings) naturally try to make sense of others by categorizing individuals into groups is a fundamental skill for the development of anti-racism that develops in childhood (Rhodes \& Baron, 2019). The tendency to socially categorize begins in infancy and evolves throughout childhood, as children interact more in their social worlds, and the types of categories (e.g., race, gender) and meanings (e.g., trait attributions) attached to categories expand. Children often show

a preference for and more positive attitudes toward their in-group (Rhodes \& Baron, 2019). This inclination toward categorization and in-group preference are important to consider as children develop notions of race and racism (Pauker et al., 2016). 
Additionally, the development of multiple classification and cognitive perspective-taking skills influence children's ideas about others (Doyle \& Aboud, 1995). Multiple classification, or the ability to classify an object or person along more than one dimension, facilitates children's understanding of themselves and others as belonging to multiple groups. Multiple classification skills allow a child to recognize, for example, "I am a girl, American, White, and a third-grade student." White children do not readily include ethnicity as a self-defining social category, instead focusing on their age and gender (Turner \& Brown, 2007). Being able to classify the self along more than one dimension (particularly when one identity is invisible within the master narrative) is critical to incorporating Whiteness into their identity. Additionally, cognitive perspective-taking enables children to understand that self and others may think or prefer different things and that both perspectives can be right (Doyle \& Aboud, 1995). The ability to accept one's own and another child's judgments as equally valid is an important skill needed to understand the experiences and ideas of others (e.g., people of color's experiences of racism).

Understanding another person's emotions is another critical skill needed for anti-racism. Empathy, which is comprised of affective and cognitive components, is "the sharing of another's emotional state; the explicit understanding of another's emotional state; and the prosocial behaviors that follow" (Dadds, et al., 2001, p. 112). The development of empathy in early adolescence aligns with the continued advancement of social perspective-taking skills, both of which have been linked to lower levels of prejudice and more positive intergroup attitudes (Doyle \& Aboud, 1995). Both empathy and perspective-taking are theorized as essential abilities for supporting youth's understanding of structural racism because they allow youth to move beyond feeling bad for people of color to linking their own experiences to others and understanding the role they play in structural racism (Thomann \& Suyemoto, 2018). 
Moral Development. Childhood is also a period of tremendous growth in children's reasoning and understanding of fairness and equality. For example, between the ages of 3 and 8 , children's decisions about how to allocate resources progresses from self-interest to a focus on equality (e.g., everyone getting the same amount; Fehr et al., 2008). However, in studies where children were told who was receiving the item, allocations of resources differed based on the recipient, with fairness only being shown towards a member of one's in-group (Fehr et al., 2009). Understanding and exploring what is fair is an important precursor to learning about individual-level bias and racism.

As children enter early adolescence, their understandings of fairness and inequality continues to develop. For example, when told there was an unequal distribution of school supplies between students of different racial backgrounds, older children (i.e., 10- to 11-yearolds) were more likely than their younger counterparts (i.e., 5- to 6-year-old) to judge the distribution as unfair, rectify the inequality by giving more resources to the disadvantaged racial group, and cite equal access and the correction of past inequalities as their reason for doing so (Elenbaas et al., 2016). Moreover, adolescents are capable of providing structural explanations of social inequalities and seek to rectify inequality when they know that it is rooted in structural discrimination (Elenbaas et al., 2020). These findings suggest that adolescents develop a more complex understanding of inequality and ability to recognize structural inequity which may influence their attribution of racism to systems and structures.

Awareness of Race. White children have an awareness of race that should be taken into consideration before embarking on anti-racist work. For example, by 4-years-old, children can categorize individuals by racial group (Pauker et al., 2016) and show a preference for children from their racial ingroup (Aboud, 1988). Although children recognize race at this young age, 
their understanding of race is limited due to under-developed socio-cognitive skills and minimal exposure to social experiences (Quintana, 2008). By ages 5 to 7, White children continue to display a preference for their ingroup and begin to show signs of prejudice toward the outgroup (Raabe \& Beelmann, 2011). For example, until about age 7, White children endorse more positive feelings and traits about White people, while ascribing more negative feelings and traits to another racial group; their expression of explicit racial biases decreases thereafter. The change in children's attitudes and behaviors during these later childhood years may be due, in part, to children's developing socio-cognitive skills and their increased understanding of social norms and expectations that make discussions of race taboo (Raabe \& Beelmann, 2011).

\section{Understanding of Self and Society in Childhood}

The development of anti-racism is built upon the foundational abilities that begin to develop during childhood. White children must develop an understanding of self and society including learning to identify as White and recognizing bias and racism at the individual level. These processes form the foundation for interpersonal anti-racism action and continued antiracist development in early adolescence.

Learn to Identify as White. We argue that the first step in the development of antiracism is to learn to identify as White. In order to develop a personal narrative that incorporates the alternative narrative of anti-racism, White children must first recognize that they have a race and begin to understand the role that race plays in their lives. However, the developmental progression of White children's racial identification is not well investigated.

The existing literature on racial identity development in childhood is scarce and what does exist focuses almost exclusively on children of color (see Rogers \& Meltzoff, 2017). Few studies have included White children in their examination of racial identity development in 
middle childhood. For example, Turner and Brown (2007) found that no White 5- to 12- year old children considered race to be one of their top three central social identities, compared to $35 \%$ of children of color. Similarly, Rogers and Meltzoff (2017) found that $89 \%$ of 7- to 12-year-old White children reported that race was not important to them. Moreover, when asked about the meaning of their race, White children often described the equality of racial groups, or claimed that being White does not mean anything (Rogers \& Meltzoff, 2017). In another study, a majority of 9- to 14-year-old White youth identified as White or Caucasian (57\%) and reported less positive feelings about their racial identity as compared with White children who identified with a hyphenated (e.g., Italian American) or ethnic/cultural/religious group (e.g., Irish; Brown et al., 2010). Taken together, these studies suggest that some White children's personal identity narratives are accommodating the master narratives of White supremacy and colorblindness through minimizing the importance of race or believing that all racial groups are equal.

Recognize Bias and Racism at the Individual Level. For children to develop into antiracists, they must be able to understand racism and recognize it when it occurs. Understanding and recognizing racism requires first having knowledge of racial stereotypes and prejudice, and then understanding that stereotypes and prejudice can lead to unfair treatment or discrimination. Previous research has shown that children have knowledge of many racial and ethnic stereotypes by age 4 or 5 (e.g., Aboud, 1988), and their knowledge of the breadth of racial stereotypes increases across the childhood years. Around the same age, children learn there are social implications of stereotypes. Although most often studied with children of color, children in elementary school recognize that racial and ethnic prejudice may lead someone to not like a member of their racial or ethnic group (Quintana, 2008). 
This developing recognition that racial stereotypes and prejudice can lead to discrimination is reflected in children's burgeoning recognition of racial discrimination. McKown (2004) found that, by the age of 10, 63\% of White children were generally aware of racism. Brown and colleagues (2011) asked White, Black, and Latinx fourth, sixth, and eighth graders if they had ever noticed or heard about an instance of racial discrimination. Among fourth graders, only $27 \%$ of White participants could name an example of racial bias, compared with $57 \%$ of Latinx and $47 \%$ of Black participants. White children were much more likely to be aware of gender bias than ethnic bias. By the time they were in sixth and eighth grades, the three ethnic groups were equally aware of ethnic bias. Thus, it seems as though children of color develop an understanding of racial bias earlier in development than White children, although White children appear to catch up by early adolescence. This difference between White children and children of color is likely due to fewer personal experiences with racism and differences in parental socialization. Across ages, Black and Latinx children are more likely than White children to have been socialized to be aware of ethnic discrimination (see Loyd \& Gaither, 2018). The result is that White children remain naïve to racism longer than children of color. Despite the overall lower rates of recognizing racism, White children recognize certain types of discrimination more easily than others. In real life examples, they most frequently point to historical examples of racism, such as Jim Crow laws forcing segregation of schools and water fountains (Brown et al., 2011). Because White parents rarely discuss racism with their children (Loyd \& Gaither, 2018), much of their knowledge stems from being taught in school about Dr. Martin Luther King and his contemporaries, typically during Black History Month. Within laboratory settings, research has shown that children as young as 6 make an attribution to racial discrimination, but only when they heard a vignette in which a White teacher showed favoritism 
to a White student over a Latinx student, and had a clear history of preferring White students (Brown, 2006). In other words, White children only perceived discrimination that was prototypical and overt. Moreover, White children's recognition of racism is influenced by master narratives. In one study, children who were exposed to a story with colorblind as compared with color-conscious messages were less likely to identify and report acts of discrimination (Apfelbaum et al., 2010).

Most evidence suggests that children more easily recognize racism that occurs at the individual as compared with a structural level. When asked about discrimination, children most frequently cite name-calling by a peer, followed by an unequal sharing of goods and social exclusion (Verkuyten et al., 1997). These behaviors are typically concrete, rather than abstract or systemic, conceptually familiar, and are cognitively easy to recognize as unfair.

\section{Interpersonal Action}

Once children are aware of racism and can recognize when it occurs, it is critical that they act. It may be easiest, developmentally, to act on the face-to-face racial discrimination they see. The anti-racism scale developed by Aldana and colleagues (2019) operationalizes anti-racist interpersonal action as: challenging or checking a friend/family member/adult (e.g., coach, teacher) who uses a racial slur or makes a racial joke, defending a friend/stranger who is the target or a racial slur or joke, talking with friends about issues of race, ethnicity, discrimination and/or segregation, and checking yourself before making a comment about race. These types of interpersonal actions are consistent with the types of discrimination children at this age are most likely to notice (e.g., Verkuyten et al., 1997).

Evidence within the bystander intervention literature suggests that bystanders who step in to stop a racist interaction are highly effective. For example, among adults, Czopp and 
colleagues (2006) have shown that confronting an instance of racial bias not only stops the racist experience, but also reduces bias by those who witness the confrontation. This is particularly influential when the confrontation comes from an individual who is not the target of bias, but rather an uninvolved bystander (Rasinski \& Czopp, 2010). This suggests that White children who "challenge or check" someone who makes a racially biased comment can be particularly effective in changing the norms supportive of racism.

Very few interventions have actually tried to teach children how to confront, and thus reduce, racism. Some work has attempted this with sexism, teaching elementary school children to respond to sexist comments they heard from peers (Lamb et al., 2009). The intervention taught children to use funny retorts or direct rebuttals to the sexist comments. The researchers found that the training intervention, particularly when children practiced the responses using roleplaying, was effective in increasing children's confrontation of sexist comments. At a six-month follow-up, the intervention effects had even spread to the children in the control condition. This suggests that children can be taught to intervene when they see individual examples of racial bias, and that this can be enhanced with clear instructions and role-playing practice.

\section{Understanding of Self and Society in Early Adolescence}

In early adolescence, the development of anti-racism builds on what happens in childhood. Moving from an individual to structural understanding of racism, White privilege, and collective action requires the more advanced foundational abilities that develop in early adolescence. However, these foundational abilities alone do not ensure the development of antiracist White youth. Promotive contexts - including ethnic-racial socialization and critical consciousness - are crucial to scaffolding a more complex understanding of self and society. 


\section{Recognize Social Inequality and Racism at the Structural Level. Although there is}

little research on the topic, in early adolescence, we assert that children become more adept at recognizing structural racism. To fully understand structural and institutional racism and discrimination, youth must understand that (a) there are social, educational, economic, and political inequalities between groups, (b) commonly-held beliefs or stereotypes can infiltrate policies, laws, media, and curricula, and (c) biased policies, laws, media, and curricula can lead to those inequalities (Brown, 2017). Developing this recognition of structural racism, over and above a recognition of individual racism, requires the socio-cognitive skills that come with early adolescence, skills that enable youth to cognitively understand how institutions and societies (in addition to individuals) can hold biases and perpetrate discrimination (Quintana, 2008).

Recognizing and understanding structural racism builds on skills and knowledge bases acquired during the preadolescent years. Children are aware, at least implicitly, that there are social status inequalities between racial groups. For example, Elenbaas and Killen (2016) found that children associated Black people with lower socioeconomic status (SES) more frequently, and associated Black people with higher SES less frequently, relative to White people, and this distinction became more profound in early adolescence. Once youth perceive racial inequalities, they can begin to understand that structural racism leads to those inequalities.

Some research has examined when White youth are aware of structural or institutional discrimination. As with individual examples of discrimination, White youth perceive structural discrimination less often than children of color (see Brown, 2017). For example, White youth were shown to have more knowledge of historical structural discrimination than Black youth (e.g., the Brown v. Board of Education case to desegregate schools), but were less likely to believe that racism is currently a social problem (Hughes \& Bigler, 2011). Similar patterns 
appear in references to national politics. Prior to the election of Barack Obama, only $58 \%$ of White children recognized existing racial disparities in who is elected President, compared to $79 \%$ of Black children (Bigler et al., 2008). Knowledge of historical structural and institutional discrimination appears to increase with age across middle childhood and into early adolescence.

Qualitative research with White youth in middle schools suggests a process by which White youth may come to understand and recognize structural racism (Thomann \& Suyemoto, 2018). After White youth learn about individual-level biases, an education about structural racism, including statistics, facts, and specific examples of fewer opportunities in jobs, education, housing, and money for people of color can foster an abstract understanding of structural racism. Only when youth focus on feeling empathy and taking the perspective of people of color can they transition from an abstract to a personal understanding of structural racism. Critically, they must also grapple with their own White identity, acknowledging their own position and privilege and the guilt that should accompany that understanding, before they embrace addressing structural racism through actions.

Understand White Privilege. Indeed, White youth have to understand structural racism and the racial hierarchy (i.e., the master narrative of White supremacy) before they can situate themselves within these systems and understand that they are at the top of the ladder for unearned reasons. In our review of the literature, we found no studies to date that directly examined White youths' understanding of privilege. In one examination of White racial identity development, most White youth did not report race as an important part of themselves and minimized the role of Whiteness in their lives often opting to identify in terms of their ethnic heritage or citing a colorblind ideology (Grossman \& Charmaraman, 2009). White privilege was brought up by only $5 \%$ of White youth when discussing their racial identity (Grossman \& 
Charmaraman, 2009). This gap in the literature is notable as scholars have outlined an awareness of racism and White privilege as central components in White racial identity development (see Helms, 2017). For White youth to engage in anti-racism, power and privilege cannot remain invisible (McIntosh, 2012). Instead, White youth need to understand their own Whiteness both in terms of a cultural group that holds meaning and a group imbued with privilege.

The master narratives of White supremacy and colorblindness allow White individuals to remove themselves from their understanding of racism, for example, by denying the existence of racism or attributing it as only individual prejudice. The belief that I am not a racist, so I am not contributing to racism is a product of White privilege and undermines one's understanding of racism as a system. Thus, it may be that avoiding an understanding of White privilege protects White individuals from negative feelings but perpetuates their racial biases (see McIntosh, 2012). We assert that experiencing negative emotions is part of the process of becoming anti-racist and that these emotions can be managed and channeled into anti-racism action.

\section{Collective Action}

Once White youth recognize racism at the structural and institutional level and understand their own privileged position in these structures, they must commit to fight racism through collective action. We argue that White youth are not anti-racist unless they engage in both interpersonal and collective action to challenge and dismantle racism at all levels. The continued resistance of the master narratives and the potential for the alternative narrative to shift them (McLean \& Syed, 2015) depends on ongoing action that works to dismantle both individual thoughts and behaviors as well as the systems and structures that uphold racial inequality.

Aldana and colleagues (2019) define communal anti-racism action as attending a meeting or joining a club on a race-related issue. Political anti-racism action includes contacting the 
media or an elected official or attending a protest about a race-related issue as well as researching and encouraging others to engage with social issues related to race. Together, communal and political anti-racist actions (i.e., collective action) challenge the systems and structures of racism. Little attention, however, has been paid to the collective anti-racism action of White youth. In one study, youth of color and White youth who discussed racial inequality at school reported behaviors that challenged individual (e.g., stopping a racist joke) and structural racism (e.g., contacting elected officials; Bañales et al., 2019). Notably, youth who reported being angry about racial inequality engaged in more interpersonal as compared with communal or political anti-racism action. Bañales and colleagues (2019) theorized that this finding might be explained by youth targeting their anger at individual perpetrators of racism rather than racist systems and structures or that opportunities for collective anti-racism action were limited.

Youth's engagement in collective anti-racism action may also be facilitated by their sense of agency and self-efficacy. For example, youth may feel like they cannot do anything to change structural racism, but they can challenge racism within their immediate environment. Thus, we assert that agency and self-efficacy are crucial aspects of collective action. White youth need to know that they have a choice in whether they contribute to racist systems and structures, but they also need to be confident in their knowledge of racism and ability to act against it.

Agency and self-efficacy are linked to the emotions that youth experience when learning about racism (e.g., hopelessness). To sustain anti-racism action, White youth must learn to address and manage the emotions (e.g., guilt, shame, fear, and anger) associated with learning about structural racism and White privilege (Helms, 2017; Thomann \& Suyemoto, 2018). The ability to cope with these emotions and channel them into action underlies a lifelong commitment to anti-racism. For example, among White adults, positive intergroup contact with 
Black Americans was related to collective action (e.g., attending protests) through the mechanisms of increased empathy and anger about injustice (Selvanathan et al., 2018).

\section{Promotive Contexts for Anti-Racism in Childhood and Early Adolescence}

White children and youth's anti-racist development is influenced by the contexts in which they spend their time. Here, we discuss two promotive contexts for the development of antiracism - ethnic-racial socialization and critical consciousness. These promotive contexts are necessary for moving White youth's understanding of racism from the individual-level to the structural-level, and toward anti-racism.

Ethnic-Racial Socialization. Ethnic-racial socialization (ERS) is broadly defined as the processes by which children are taught and learn about race and ethnicity at both proximal- (e.g., family, school) and distal- (e.g., media) levels (Loyd \& Gaither, 2018). White children and youth primarily experience colorblind ERS or silence about race from their parents and teachers (see Loyd \& Gaither, 2018). There is a dearth of research examining the promotive effect of ERS for White children and youth.

Instead, research has focused on the content or goals of ERS. For example, Gillen-O'Neel and colleagues (2021) explored the goals that progressive White parents had for socializing their children about race. Findings indicated that many parents wanted their children to understand individual and structural racism, be aware of their privilege, take individual action against racism, and understand that making mistakes is part of learning about and challenging racism. While this study stopped short of examining the practices associated with these goals, it is one of few explorations of White parents who plan to talk (and likely have talked) about race and racism with their children. Perry and colleagues (2020) are among the first to report that White parents' color-conscious ERS can reduce their children's anti-Black attitudes. Specifically, in 
their study, White children's implicit anti-Black attitudes decreased after having conversations about racism (scaffolded by a video scenario and prompts) with their parents. Moreover, parents' discomfort when talking about race (e.g., tenseness, physiological arousal) did not increase children's anti-Black attitudes (Perry et al., 2020).

ERS within the school context is also promotive for White children's anti-racism development. Indeed, the tenets of anti-bias education (i.e., develop self-awareness and positive identities, value diversity, recognize unfairness, and act against prejudice; Derman-Sparks \& Edwards, 2010) align with aspects of our developmental model. In the classroom, explicitly discussing systems of oppression (i.e., anti-bias education) and racism specifically (i.e., antiracist education) are central to promoting children's understanding of self and society. Some evidence suggests that teaching children about racism can lead to reductions in racial prejudice. Interventions that have taught about racism, specifically lessons about the historical discrimination faced by famous Black individuals, showed a reduction in children's prejudice (i.e., they held more positive and less negative attitudes after the intervention relative to a control condition) and a greater valuing of racial fairness. White children who learned about historical discrimination showed a slight increase in feeling defensive and more guilty following the interventions, although that was predictive of having more positive attitudes (Hughes et al., 2007). Thus, teaching full histories and connecting historical to contemporary racism are strategies that promote White children's recognition of bias and racism at the individual level.

The above studies indicate promotive aspects of ERS for White children and youth. However, more research is warranted. For example, while some White parents wanted their children to be aware of their privilege, many of them were negotiating what racial identity looks like for themselves and their children (Gillen-O’Neel et al., 2021). A first step towards 
promoting ant-racism, then, may be that White parents learn to identify as White so that they can teach their children that being White is a racial identity with cultural meaning.

In addition, little research to date has examined the ERS strategies used to teach youth about structural racism, White privilege, and engaging in collective action. This lack of support may be explained by adults' discomfort or lack of knowledge about race and racism that (see Gillen-O'Neel et al., 2021). It may be that talking about race-related issues even when it is uncomfortable, making mistakes and learning from them, and involving children in these processes will encourage children and youth to learn more and develop anti-racist attitudes and behaviors. Finally, ERS that promotes anti-racism action likely includes adults providing children and youth with clear instructions, examples, and role-playing opportunities for how to interrupt racial discrimination. White adults can also model this interpersonal anti-racist action, for example, by calling out individuals who say racial slurs or jokes in front of children.

As Rogers (2019) aptly points out, in developmental research, inequality tends to be conflated with poverty and oppression rather than wealth and privilege. The racial identity literature, too, “primarily examines and conceptualizes the 'Black' side of the racialized hierarchy... leaving 'Whiteness' and racial privilege vastly underexamined” (Rogers, 2019, p. 587). To better understand how adults can support anti-racist development, developmental researchers must expand our study of ERS to include how to teach youth about White privilege and racial inequality.

Critical Consciousness. Critical consciousness includes the processes of critical reflection (i.e., awareness of historical and contemporary oppression and inequality), critical motivation (i.e., a commitment to address inequality), and critical action (i.e., action that challenges inequality; Heberle et al., 2020; Diemer et al., 2020). Although it has primarily been 
examined at the individual level, critical consciousness also operates at the contextual level "where it reflects the values, culture, and norms" of children's home and school context (Heberle et al., 2020, p. 544). While there is growing body of research on the development of critical consciousness during adolescence and young adulthood, we were not able to identify any such research with children (see also Heberle et al., 2020). Moreover, adolescent researchers have only recently begun to explore how critical consciousness operates for White youth as compared with youth of color (Bañales et al., 2019). Thus, an important direction for future research is to examine how and why some White youth move away from racial biases of childhood and toward enduring anti-racist beliefs and actions.

Children may have an inclination for critical consciousness in childhood as evident by their preference for fairness and ability to recognize, reason about, and resist inequality (Elenbaas et al., 2020; Rogers, 2019). Moreover, they recognize social inequalities (e.g., unequal access to school supplies), are able to reason about why inequalities exist (e.g., based on merit), and seek to rectify the inequality (e.g., distribute more resources to disadvantaged groups; Elenbaas et al., 2020). While children have a natural tendency to resist inequality and favor fairness, this inclination declines across childhood as children become more aware of social norms (Rogers, 2019). Thus, fostering these tendencies during childhood may promote critical consciousness later in life (Rogers, 2019).

Scholars have recently begun to question what critical consciousness looks like for White youth (Diemer et al., 2020; Tyler et al., 2020). Diemer and colleagues (2020) suggest that, for those with privileged identities, critical reflection (e.g., similar to recognizing structural inequality and understanding White privilege in our model) is a necessary precursor to engaging in critical action (e.g., collective action in our model). Tyler and colleagues (2020) explored 
White youth's engagement in critical reflection about race and SES. Results indicated that White youth engaged in lower levels of critical reflection in terms of race as compared with Black youth. Further, White youth with higher levels as compared with lower levels of critical reflection (i.e., based on both race and SES) were less empathetic. Thus, critical reflection may create instability in White youths' understanding of systems and structures or prompt defense mechanisms like White guilt or White fragility (Tyler et al., 2020). We hypothesize that the ability to manage one's emotional reactions to learning about oppression is necessary to support White youth's critical reflection so that they can engage in critical action.

Similar to ERS, home and school contexts promote youth's critical consciousness. Research has demonstrated that having discussions about inequality at home or at school are associated with higher levels of critical consciousness even for White youth (see Bañales et al., 2019; Heberle et al., 2020). Indeed, critical consciousness socialization (e.g., discussions about racial inequality and social issues) may be a missing aspect of ERS in which adults support youth's understanding of systems of oppression. Youth who received critical consciousness messages, compared with colorblind socialization messages, at school were more likely to engage in anti-racism action (Bañales et al., 2019). The promotive aspects of critical consciousness for the development of anti-racist White youth may be supported by ERS.

\section{Research Agenda for Studying the Development of Anti-Racist White Children and Youth}

The limited existing research on the development anti-racist White children and youth highlights the critical urgency for future scholarship on this topic. Across bodies of literature (e.g., identity development, critical consciousness), examinations of inequality have focused more on the experiences of marginalized children and youth and less on the experiences of privileged children and youth (Rogers, 2019). This contributes to the normalization of Whiteness 
and the invisibility of White privilege. It is imperative that researchers attend to how White youth understand the self and society by recognizing and then resisting the master narratives of White supremacy and colorblindness. We propose four directions for future research:

(1) Developmental scientists must examine Whiteness - how White children and youth learn to recognize it, internalize it, and, importantly, dismantle it. Research examining White children's racial identity development and associations with their understanding of White privilege in early adolescence is imperative. Relatedly, there is a demonstrated need to explore White youths' understanding and negotiation of White privilege. We also call for more research examining how ERS across multiple contexts, including at home, school, and in the media promote youth's understanding of Whiteness and White privilege. For example, we know little about how White youth in majority White spaces are learning about Whiteness and racism.

(2) Researchers should continue to explore strategies for moving White children from recognizing bias and racism at the individual level to an understanding and awareness that racism is a structural phenomenon. We call for more research that examines ERS practices that teach White youth about structural racism and White privilege. Importantly, research must critically examine what anti-racist ERS looks like for White youth and what messages promote (versus inhibit) the development of anti-racism.

(3) It is important to extend the study of critical consciousness in two ways. First, researchers should focus on the development (or precursors) of critical consciousness in childhood. Second, researchers should continue to probe what the processes of critical reflection, motivation, and action look like for White youth (see Diemer et al., 2020). Supporting White children and youth's understanding of social inequality is crucial for moving them towards a commitment to interpersonal and collective anti-racism action. We need to know more about 
how and why some White youth move away from racial biases of childhood and toward enduring anti-racist beliefs and actions. Researchers should investigate the link between children and youth's attitudes and behaviors at both the individual- and structural-level to better understand what motivates them to move from being non-racist to anti-racist actions.

(4) Finally, there is a demonstrable need for longitudinal research and research from an intersectional perspective. In each of the areas described above, longitudinal research is needed to track developmental changes across childhood and adolescence. An intersectional approach is also warranted. As with all children and youth, White youth hold multiple identities that influence their experiences and development of anti-racism. White youth who hold marginalized identities (e.g., sexual orientation, low-SES) may have an easier time resisting the master narratives of White supremacy and colorblindness (Syed \& McLean, 2020). Notably, scholars must also seek to understand how those who hold only privileged identities (i.e., White Christian affluent cisgender males) develop anti-racism.

\section{Conclusion}

To more fully understand the development of anti-racism in early adolescence, we must understand what is happening in the preceding years. Extant research is compartmentalized within a specific developmental period (e.g., racial stereotype research focuses on young White children; ethnic-racial identity and critical consciousness focuses on youth of color). In contrast, we call for building bridges and connections across development, and collaborations among childhood and adolescent researchers. To facilitate bridge-building, we propose a developmental model of anti-racism across childhood and early adolescence. The pillars of our proposed bridge include foundational socio-cognitive abilities and moral capacities, an emerging understanding of self and society, engagement in action, and promotive contexts that contribute to anti-racism. 
Our developmental model is situated within a "structural-psychological approach" to anti-racism in which the master narratives of White supremacy and colorblindness are treated as everyday aspects of White children and youth's understanding of self and society. We focus on the processes necessary for White children and youth to resist master narratives and instead actively incorporate an alternative narrative of anti-racism into their personal narratives. By taking a wider developmental lens, we conclude with a mandate for studying the development of White resisters - anti-racist White children and youth who recognize racism and White privilege and actively seek to challenge it - across development. 


\section{References}

Aboud, F. (1988). Children and prejudice. New York: Blackwell.

Apfelbaum, E. P., Pauker, K., Sommers, S. R., \& Ambady, N. (2010). In blind pursuit of racial equality? Psychological Science, 21(11), 1587-1592. https://doi.org/10.1177/0956797610 384741

Aldana, A., Bañales, J., \& Richards-Schuster, K. (2019). Youth anti-racist engagement: Conceptualization, development, and validation of an anti-racism action scale. Adolescent Research Review, 4(4), 369-381. https://doi.org/10.1007/s40894-019-00113-1

Bañales, J., Aldana, A., Richards-Schuster, K., Flanagan, C. A., Diemer, M. A., \& Rowley, S. J. (2019). Youth anti-racism action: Contributions of youth perceptions of school racial messages and critical consciousness. Journal of Community Psychology, 1-22. https://doi.org/10.1002/jcop.22266

Bigler, R. S., Arthur, A. E., Hughes, J. M., \& Patterson, M. M. (2008). The politics of race and gender: Children's perceptions of discrimination and the US presidency. Analyses of Social Issues and Public Policy, 8(1), 83-112.

Brown, C. S. (2006). Bias at school: Perceptions of racial/ethnic discrimination among Latino and European American children. Cognitive Development, 21(4), 401-419. https://doi.org/10.1016/j.cogdev.2006.06.006

Brown, C. S. (2017). Discrimination in childhood and adolescence: A developmental intergroup approach. Psychology Press.

Brown, C. S., Spatzier, A., \& Tobin, M. (2010). Variability in the inter-group attitudes of White children: What we can learn from their ethnic identity labels. Social Development, 19(4), 758-778. https://doi.org/10.1111/j.1467-9507.2009.00571.x 
Brown, C. S., Alabi, B. O., Huynh, V. W., \& Masten, C. L. (2011). Ethnicity and gender in late childhood and early adolescence: group identity and awareness of bias. Developmental Psychology, 47(2), 463-471. https://doi.org/10.1037/a0021819

Czopp, A. M., Monteith, M. J., \& Mark, A. Y. (2006). Standing up for a change: Reducing bias through interpersonal confrontation. Journal of Personality and Social psychology, 90(5), 784. https://doi.org/10.1037/0022-3514.90.5.784

Dadds, M. R., Hunter, K., Hawes, D. J., Frost, A. D. J., Vassallo, S., Bunn, P., Merz, S., \& Masry, Y. E. (2007). A measure of cognitive and affective empathy in children using parent ratings. Child Psychiatry and Human Development, 39(2), 111-122. https://doi.org/10.1007/s10578-007-0075-4

Derman-Sparks, L., \& Edwards, J. O. (2010). Anti-bias education for young children and ourselves (Vol. 254). National Association for the Education of Young Children.

Diemer, M. A., Pinedo, A., Bañales, J., Mathews, C. J., Frisby, M. B., Harris, E. M., \& McAlister, S. (2020). Recentering Action in Critical Consciousness. Child Development Perspectives. https://doi.org/10.1111/cdep.12393

Doyle, A. B., \& Aboud, F. E. (1995). A longitudinal study of White children's racial prejudice as a social-cognitive development. Merrill-Palmer Quarterly, 41(2), 209-228.

Elenbaas, L., Rizzo, M. T., Cooley, S., \& Killen, M. (2016). Rectifying social inequalities in a resource allocation task. Cognition, 155, 176-187. https://doi.org/10.1016/j.cognition $\underline{.2016 .07 .002}$

Elenbaas, L., Rizzo, M. T., \& Killen, M. (2020). A developmental-science perspective on social inequality. Current Directions in Psychological Science, 29(6), 610-616. https://doi.org/10.1177/0963721420964147 
Elenbaas, L., \& Killen, M. (2016). Age-related changes in children's associations of economic resources and race. Frontiers in Psychology, 7. https://doi.org/10.3389/fpsyg.2016.00884

Fehr, E., Bernhard, H., \& Rockenbach, B. (2008). Egalitarianism in young children. Nature, 454 (7208), 1079-1083. https://doi.org/10.1038/nature07155

Gillen-O’Neel, C., Huynh, V. W., Hazelbaker, T., \& Harrison, A. (2021). From kindness and diversity to justice and action: White parents' ethnic-racial socialization goals. Journal of Family Issues. https://doi.org/10.1177/0192513X21996392

Grossman, J. M., \& Charmaraman, L. (2009). Race, context, and privilege: White adolescents' explanations of racial-ethnic centrality. Journal of Youth and Adolescence, 38(2), 139152. https://doi.org/10.1007/s10964-008-9330-7

Heberle, A. E., Rapa, L. J., \& Farago, F. (2020). Critical consciousness in children and adolescents: A systematic review, critical assessment, and recommendations for future research. Psychological Bulletin, 146(6), 525-551. https://doi.org/10.1037/bul0000230

Helms, J. E. (2017). The challenge of making Whiteness visible: Reactions to four Whiteness articles. The Counseling Psychologist, 45(5), 717-726. https://doi.org/10.1177/0011000 $\underline{017718943}$

Hughes, J. M., Bigler, R. S., \& Levy, S. R. (2007). Consequences of learning about historical racism among European American and African American children. Child Development, 78(6), 1689-1705. https://doi.org/10.1111/j.1467-8624.2007.01096.x

Hughes, J. M., \& Bigler, R. S. (2011). Predictors of African American and European American adolescents' endorsement of race-conscious social policies. Developmental Psychology, 47, 479-492. https://doi.org/10.1037/a0021309

Lamb, L. M., Bigler, R. S., Liben, L. S., \& Green, V. A. (2009). Teaching children to confront 
peers' sexist remarks: Implications for theories of gender development and educational practice. Sex Roles, 61(5-6), 361-382. https://doi.org/10.1007/ s11199-009-9634-4

Loyd, A. B., \& Gaither, S. E. (2018). Racial/ethnic socialization for White youth: What we know and future directions. Journal of Applied Developmental Psychology, 59, 54-64. https://doi.org/10.1016/j.appdev.2018.05.004

McIntosh, P. (2012). Reflections and future directions for privilege studies. Journal of Social Issues, 68(1), 194-206. https://doi.org/10.1111/j.1540-4560.2011.01744.X

McKown, C. (2004). Age and ethnic variation in children's thinking about the nature of racism. Journal of Applied Developmental Psychology, 25(5), 597-617. https://doi.org/10.1016/j. appdev.2004.08.001

McLean, K. C., \& Syed, M. (2015). Personal, master, and alternative narratives: An integrative framework for understanding identity development in context. Human Development, 58 (6), 318-349. https://doi.org/10.1159/000445817

Neville, H. A., Awad, G. H., Brooks, J. E., Flores, M. P., \& Bluemel, J. (2013). Color-blind racial ideology: Theory, training, and measurement implications in psychology. American Psychologist, 68(6), 455-466. https://doi.org/10.1037/a0033282

Pauker, K., Williams, A., \& Steele, J. R. (2016). Children's racial categorization in context. Child Development Perspectives, 10, 33-38. https://doi.org/10.1111/cdep.12155

Perry, S., Skinner-Dorkenoo, A. L., Abaied, J., Osnaya, A., \& Waters, S. F. (2020). Exploring how parent-child conversations about race influence children's implicit biases. https://doi.org/10.31234/osf.io/3xdg8 
Quintana, S. M. (2008). Racial perspective taking ability: Developmental, theoretical, and empirical trends. In C. McKown \& S. M. Quintana (Eds.), Handbook of Race, Racism, and the Developing Child (pp. 16-35). Wiley.

Raabe, T., \& Beelmann, A. (2011). Development of ethnic, racial, and national prejudice in childhood and adolescence: A multinational meta-analysis of age differences. Child Development, 82(6), 1715-1737. https://doi.org/10.1111/j.1467-8624.2011.01668.x

Rasinski, H. M., \& Czopp, A. M. (2010). The effect of target status on witnesses' reactions to confrontations of bias. Basic and Applied Social Psychology, 32(1), 8-16. https://doi.org/10.1080/01973530903539754

Rhodes, M., \& Baron, A. (2019). The development of social categorization. Annual Review of Developmental Psychology, 1(1), 359-386. https://doi.org/10.1146/annurev-devpsych$121318-084824$

Richeson, J. A., \& Sommers, S. R. (2016). Toward a social psychology of race and race relations for the twenty-first century. Annual Review of Psychology, 67, 439-463. https://doi.org/ 10.1146/annurev-psych-010213-115115

Roberts, S. O., \& Rizzo, M. (2020). The psychology of American racism. American Psychologist. Advance online publication. https://dx.doi.org/10.1037/amp0000642

Rogers, L. O. (2019). Commentary on economic inequality: "What" and "who" constitutes research on social inequality in developmental science? Developmental Psychology, 55 (3), 586-591. http://dx.doi.org/10.1037/dev0000640.

Rogers, L. O., \& Meltzoff, A. N. (2017). Is gender more important and meaningful than race? An analysis of racial and gender identity among Black, White, and mixed-race children. Cultural Diversity and Ethnic Minority Psychology, 23(3), 323-334. 
https://doi.org/10.1037/cdp0000125

Seaton, E. (2020, June 30). Becoming an antiracist society: Setting a developmental research agenda [Webinar]. Society for Research on Child Development.

Selvanathan, H. P., Techakesari, P., Tropp, L. R., \& Barlow, F. K. (2018). Whites for racial justice: How contact with Black Americans predicts support for collective action among White Americans. Group Processes \& Intergroup Relations, 21(6), 893-912. https://doi.org/10.1177/1368430217690908

Syed, M., \& McLean, K. C. (2020). Master narrative methodology: A primer for conducting structural-psychological research [Manuscript under review].

Tatum, B. D. (2017). Why are all the Black kids sitting together in the cafeteria? Basic Books.

Thomann, C. R., \& Suyemoto, K. L. (2018). Developing an antiracist stance: How White youth understand structural racism. The Journal of Early Adolescence, 38(6), 745-771. https://doi.org/10.1177/0272431617692443

Turner, K. L., \& Brown, C. S. (2007). The centrality of gender and ethnic identities across individuals and contexts. Social Development, 16(4), 700-719. https://doi.org/10.1111/j.1467-9507.2007.00403.x

Tyler, C. P., Olsen, S. G., Geldhof, G. J., \& Bowers, E. P. (2020). Critical consciousness in late adolescence: Understanding if, how, and why youth act. Journal of Applied Developmental Psychology, 70, 101165. https://doi.org/10.1016/j.appdev.2020.101165

U.S. Census (2020). 2020 census questions : Race. https://2020census.gov/en.html

Verkuyten, M., Kinket, B., \& van der Wielen, C. (1997). Preadolescents' understanding of ethnic discrimination. The Journal of Genetic Psychology, 158(1), 97-112. https://doi.org/10.1080/00221329709596655 


\section{Figure 1}

\section{Development Model of Anti-Racism Among White Children and Youth}

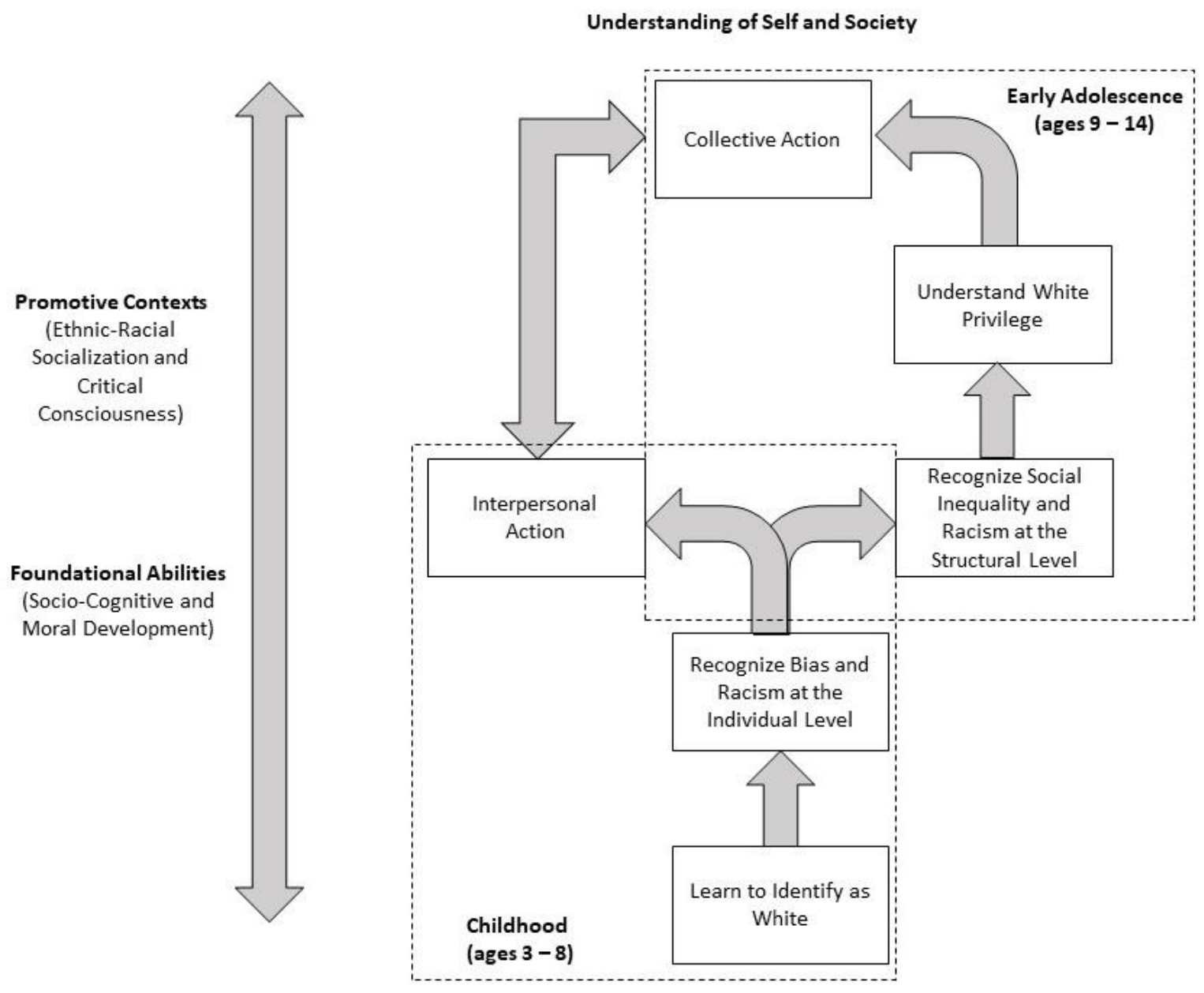

